\title{
Nurses Barrier: A Patient Safety Concern in The Intensive Care Unit
}

\author{
Gunawan Gunawan ${ }^{1^{*}}$ (1) \\ Hanik Endang Nihayati ${ }^{2}$ \\ Listyaning Puspita Sari ${ }^{3}$ \\ Muhammad Ali Machrus ${ }^{4}$ \\ 1 Spv of BPJS Hospitalization \\ Service, Primasatya Husada Citra \\ Hospital, Surabaya, Indonesia \\ 2 Department of Advanced Nursing, \\ Faculty of Nursing, Universitas \\ Airlangga, Surabaya, Indonesia \\ 3 Intensive Care Unit, Primasatya \\ Husada Citra Hospital, Surabaya, \\ Indonesia \\ 4 Operating Theater Unit, Primasatya \\ Husada Citra Hospital, Surabaya, \\ Indonesia \\ *Correspondence: Gunawan \\ Gunawan \\ Spv of BPJS Hospitalization Service, \\ Primasatya Husada Citra Hospital, \\ Surabaya, Indonesia. \\ Tel: +62 81330608440 \\ Email: gunawan.phc@gmail.com
}

Volume 1(1), 25-27

(C) The Author(s) 2022

http://dx.doi.org/10.55048/jpns.v1i1.2

e-ISSN 2827-8100

p-ISSN 2827-8496

Received : December 29, 2021

Revised : January 1, 2022

Accepted : January 2, 2022

Published: January 22, 2022

\section{(i)}

This is an Open Access article distributed under the terms of the Creative Commons Attribution-NonCommercial 4.0 International License.

\begin{abstract}
Patient safety became one of the most important indicators in maintaining the quality of nursing service in the hospital. Patient, individual staff, team, task and technology, work environment, organizational and management, and institutional context factors are all examples of obstacles nurses encounter when attempting to ensure patient safety in the hospital setting. Lastly, nurses should put concern in patient safety to make sure the quality by considering the behaviour and refer to Laurence Green Theory.
\end{abstract}

Keywords: patient safety; nurse; intensive care unit; barrier

In the hospitals, patient safety is a significant source of concern. Not just for the hospital's administration but also the healthcare professionals engaged, such as physicians, nurses, and other healthcare professionals. Within the first 48 hours of a patient's admission to the Intensive Care Unit(ICU), predisposing variables contributed to the patient's emergency. In the ICU, the mistake rate is higher because nurses are more focused on patient care and collaborative activities with other medical workers, which causes nursing documentation to be less accurate and efficient. This might happen when nurses are experiencing an increase in their nursing burden, resulting in them making mistakes (Kang et al., 2016). The actions that necessitate nurses to act quickly, making patient identification with bracelets ineffective. As a result, nurses' nursing documentation is not as adequate as possible. Nurse communication (documentation) failures in the intensive care unit can result in mistakes in documentation, insufficient paperwork, and only a small number of patients meeting documentation requirements (Nursalam, 2016).

There are many different types of medications, treatments, and tests available in hospitals and medical equipment that use modern technology. Along with the advancement of research and technology, the complexity of healthcare services supplied by healthcare and non-healthcare personnel is expanding (Thimbleby, 2013). Consequently, unfavourable events can occur if the complexity is not effectively controlled. The nursing staff is the most numerous and longest-interacting human resource with patients. The nursing staff is on call 24 hours

Gunawan, G, Nihayati, H. E., Puspita L., \& Machrus, M. A. (2022). Nurses Barrier: A Patient Safety Concern in The Intensive Care Unit. The Journal of Palembang Nursing Studies. 1(1): 25-27. http://dx.doi.org/10.55048/jpns.v1i1.2 
a day, seven days a week, to accompany and monitor patient health constantly and continuously to give comprehensive and professional nursing care. Nurses make many mistakes due to their heavy workload and their combined efforts with other health care professionals. This can result in adverse events that have a negative influence on patient safety. Failure to ensure patient safety correctly and adequately can result in the transmission of infections, medication administration mistakes, and treatments that can result in permanent damage or even death in patients if not done correctly and appropriately. Patient, individual staff, team, task and technology, work environment, organizational and management, and institutional context factors are all examples of obstacles nurses encounter when attempting to ensure patient safety in the hospital setting (Ridelberg et al., 2014).

As a result, an approach based on Lawrence Green's theory of human behaviour must be used to determine human behaviour from the level of health, which suggests that behaviour is formed by several factors, one of which is predisposing factors, which include knowledge, attitudes, and motivation, must be used to determine human behaviour from the level of health. Lawrence Green is credited with developing this hypothesis, first proposed in 1980. It attempts to understand human behaviour from the standpoint of health. Two essential elements impact the health of an individual or a society: factors caused by conduct and factors that are not caused by behaviour (Lawrence, 2007; Lawrence \& Kinn, 2013).

Behaviour is influenced by three main factors, summarized in the acronym PRECEDE. Predisposing, Enabling and Reinforcing Causes in Educational Diagnosis and Evaluation. PRECEDE is a direction to follow when assessing or diagnosing, and evaluating behaviour in the context of health education (promotion) activities. PRECEDE is a stage in the process of analysing an issue. The preceding processes or phases are divided into five categories. It is necessary to assess the overall quality of life and the social issues and demands of a particular community in the first stage. The second stage is determining the health factors of the problem and the need identified. The third stage entails investigating the behavioural and environmental factors that influence the development of health issues. The fourth step involves identifying the elements that influence, reinforce, and enable behaviour and lifestyle choices. Five-stage intervention planning consists of determining which health promotion, education or policy-related interventions are most effective in inducing desired changes in behaviour or environment and which factors support those changes in behaviour and environment to achieve the desired results (Binkley \& Johnson, 2013; James et al., 2021).

Furthermore, this Precede model can be described as the behaviour itself is determined or formed from 3 factors: 1) Predisposing factors that are manifested in knowledge, attitudes, motivation, beliefs, beliefs, values, and so on. 2) Enabling factors to manifest in the physical environment, the availability or unavailability of health facilities or facilities. 3) Reinforcing factors, which are manifested in the attitudes and behaviour of health workers, or other officers, which are a reference group for community behaviour. Meanwhile, PROCEED: Policy, Regulatory, Organizational Construct in Educational and Environmental Development is a direction in planning, implementing, and evaluating health education (promotion). If PROCEED is the problem diagnosis phase, then proceed is the planning, implementation and evaluation of health promotion. Proceed consists of four additional stages. In the sixth stage, the interventions identified in the fifth stage are implemented. The seventh stage requires evaluation of the intervention process. The eighth stage involves evaluating the impact of the intervention on the factors supporting the behaviour and on the behaviour itself. The ninth and final stage, consisting of outcome evaluation, is to determine the final effect of the intervention on the health and quality of life of the population (Bahadori et al., 2021; Guevarra et al., 2021).

Laurence Green's theory provides accurate information and description in the implementation of patient safety which includes three factors, namely predisposing, enabling, and reinforcing factors. This can be the right foundation for nurses to carry out patient safety. Finally, nurses may effectively adopt and enforce patient safety if they take appropriate strategies and behaviours. Patient satisfaction with the quality of service may be improved in this manner, and the quality of service in safeguarding patients while they are having treatment at the hospital can be guaranteed.

Gunawan, G, Nihayati, H. E., Puspita L., \& Machrus, M. A. (2022). Nurses Barrier: A Patient Safety Concern in The Intensive Care Unit. The Journal of Palembang Nursing Studies. 1(1): 25-27. http://dx.doi.org/10.55048/jpns.v1i1.2 


\section{Declaration of Interest}

None

\section{Acknowledgment}

None

\section{Funding}

None

\section{Data Availability}

None

\section{References:}

Bahadori, F., Ghofranipour, F., Zarei, F., Ziaei, R., \& Ghaffarifar, S. (2021). Application of the PRECEDE -PROCEED model in prevention of brucellosis focused on livestock vaccination process. $B M C$ Vet Res, 17(1), 384. https://doi.org/10.1186/ s12917-021-03099-y

Binkley, C. J., \& Johnson, K. W. (2013). Application of the PRECEDE-PROCEED Planning Model in Designing an Oral Health Strategy. Journal of theory and practice of dental public health, 1(3), https://pubmed.ncbi.nlm.nih. gov/25328904

Guevarra, J. P., Peden, A. E., \& Franklin, R. C. (2021). Application of the PRECEDEPROCEED model in the development of evidence-informed interventions for drowning prevention: a mixedmethods study protocol. BMJ OPEN, 11(7), e050688. https://doi.org/10.1136/ bmjopen-2021-050688

James, T. G., Varnes, J. R., Sullivan, M. K., Cheong, J., Pearson, T. A., Yurasek,
A. M., Miller, M. D., \& McKee, M. M. (2021). Conceptual Model of Emergency Department Utilization among Deaf and Hard-of-Hearing Patients: A Critical Review. Int $\mathrm{J}$ Environ Res Public Health, 18(24). https://doi.org/10.3390/ ijerph182412901

Kang, J.-H., Kim, C.-W., \& Lee, S.-Y. (2016). Nurse-Perceived Patient Adverse Events depend on Nursing Workload. Osong Public Health and Research Perspectives, 7(1), 56-62. https:// doi.org/https://doi.org/10.1016/j. phrp.2015.10.015

Lawrence, D. J. (2007). The four principles of biomedical ethics: a foundation for current bioethical debate. J Chiropr Humanit, 14, 34-40.

Lawrence, M., \& Kinn, S. (2013). Needs, priorities, and desired rehabilitation outcomes of family members of young adults who have had a stroke: Findings from a phenomenological study. Disabil Rehabil, 35(7), 586-595. https://doi.org/1 $0.3109 / 09638288.2012 .711895$

Nursalam. (2016). Metodologi Penelitian IImu Keperawatan (4 ed.). Jakarta: Salemba Medika.

Ridelberg, M., Roback, K., \& Nilsen, P. (2014). Facilitators and barriers influencing patient safety in Swedish hospitals: a qualitative study of nurses' perceptions. BMC Nursing, 13(1), 23. https://doi. org/10.1186/1472-6955-13-23

Thimbleby, H. (2013). Technology and the future of healthcare. Journal of Public Health Research, 2(3), e28-e28. https:// doi.org/10.4081/jphr.2013.e28 